\title{
BUSINESS DEVELOPMENT STRATEGY OF \\ HONEY PINEAPPLE (Ananas comosus (L) Merr) PROCESSED PRODUCTS IN VITA NAS, BELIK DISTRICT, PEMALANG REGENCY
}

\author{
Eka Amelia, Lutfi Aris Sasongko, Hendri Wibowo \\ Fakultas Pertanian Universitas Wahid Hasyim \\ Email : wibowohendri9@gmail.com
}

\begin{abstract}
Abstrak
Honey Pineapple, one of the horticultural crops, can be made as a processed product. This research aims to analysis external internal factors, as well as to formulate alternative business development strategy of honey pineapple products in Vita Nas belik District, Pemalang Regency.Vita Nas has three types of products, namely pineapple syrup products, pineapple juice drinks and pineapple cocktails. Each product has different packaging. The data types used are primary and secondary. The method of data analysis is done by using IFE matrix, EFE matrix, IE matrix and SWOT matrix. The results of internal factors analysis (strength) include having a record of each sale, abundant raw materials, products have distinctive features, product diversification, the presence of training and the supply of labor skills, organizational structure is good and has adequate equipment. Internal factors (weakness) include the minimum use of websites and internet media, marketing area only in penday an its surrounding, the absence of sales marketing and a narrow packing place. External factors (opportunities) include cooperation with other entrepreneurs, the price stability of raw materials, have reular consumers and the support of local governments. External factors (threats) include rely on middle men, consumer preterences and the price is relatively expensive. Alternative strategies that can be done are: (1) strengthening cooperation between entrepreneurs and local governments, making the latest innovations with other entrepreneurs and developing product quality assurance; (2) Improve product promotion; (3) Establish direct cooperation with farmers, maintain product quality and provide the best service; (4) Improve promotional activities with websites and internet media.
\end{abstract}

Keywords: Strategy, Processed, Honey Pineapple, SWOT.

\section{PENDAHULUAN}

Pertanian merupakan salah satu sektor yang sangat dominan dalam mata pencaharian masyarakat di Indonesia karena mayoritas penduduk Indonesia bekerja sebagai petani. Proses produksi pertanian melibatkan hal-hal teknis seperti bibit berkualitas, teknik menanam komoditas tertentu, dan lain sebagainya Dwiastuti (2017).

Kecamatan Belik dikenal dengan dengan salah satu komoditas hortikulturanya yang dikembangkan secara turun temurun yaitu nanas madu (Ananas comosus (L) Merr). Hampir di sepanjang jalan dari Kabupaten Pemalang menuju Kecamatan Belik banyak sekali perkebunan nanas yang tumbuh dan berkembang dengan sangat baik. Mayoritas penduduk Kecamatan Belik yaitu petani nanas. Biasanya nanas madu dijual dalam bentuk buah segar ataupun olahan. Kecamatan Belik memiliki hasil luas panen dan produksi nanas terbesar dari tahun 2014-2015 di Kabupaten Pemalang. (BPS 2016).

Budidaya buah nanas yang substansial terutama dilakukan di wilayah selatan Ethiopia (Sidama dan Gojeb). Petani kecil terbiasa bekerja dengan nanas sebagai tanaman komersial dalam sistem pertanian campuran selama beberapa dekade. (Agrotorestry, 2019).

Fitri, dkk (2014) dalam penelitiannya yang berjudul "Strategi Pengembangan Agribisnis Nenas Di Kabupaten Kubu Raya Kalimantan Barat". Menunjukkan bahwa beberapa faktor yang mempengaruhi pengembangan nanas adalah ketersediaan nanas, sistem manajemen petani,ketersediaan program pembangunan berkelanjutan dan daya saing produk dengan buah impor yang masih rendah.

Astoko, (2019) hasil penelitian (1) Agroekologi cocok dipadukan dengan kualitas sumber daya manusia akan mampu menghasilkan buah nanas unggul berkualitas dan kontinuitas, (2) Ketersediaan bibit hasil penangkaran sendiri yang unggul, ketersediaan lahan, pengembangan varietas baru yang dipadukan dengan adopsi teknologi kultur jaringan akan mampu menciptakan 
nanas unggul berkualitas dan kontinuitas.(3) Produksi nanas yang unggul harus didukung oleh ketersediaan sarana produksi yang memadai, kelembagaan petani yang mantap dan profesional serta kebijakan pemerintah yang memihak kepada petani nanas. (4) Strategi pemasaran yang tepat sasaran, adanya industri pengolahan nanas serta didukung kebijakan moneter yang menguntungkan bagi petani nanas.

Tujuan dari penelitian ini adalah mengidentifikasi faktor-faktor lingkungan internal (kekuatan dan kelemahan) dan faktor-faktor eksternal (peluang dan ancaman) pada usaha olahan nanas madu di Vita Nas serta merumuskan dan memberikan strategi pengembangan alternatif usaha olahan nanas madu di Vita Nas Kecamatan Belik Kabupaten Pemalang.

\section{METODE PENELITIAN}

Metode dasar dalam penelitian ini menggunakan metode deskriptif. Sedangkan untuk metode pelaksanaanya menggunakan metode survei. Sumber data yang digunakan dalam penelitian ini meliputi data primer dan data sekunder. Responden pada penelitian ini berjumlah 20 orang. Data yang terkumpul dianalisis dengan menggunakan analisis uji validitas dan reliabitas, matriks IFE/EFE, dan SWOT.

Kuesioner merupakan salah satu alat yang paling banyak digunakan untuk mengumpulkan data khususnya dalam penelitian ilmu sosial. Tujuan utama kuisioner dalam penelitian adalah untuk mendapatkan informasi yang relevan dengan cara yang paling reliabel dan valid. Dengan demikian keakuratan dan konsistensi survei / kuesioner merupakan aspek penting dari metodologi penelitian yang dikenal sebagai validitas dan reliabilitas (Taherdoost, 2018).

\section{HASIL DAN PEMBAHASAN}

\section{Sejarah Vita Nas}

Sejarah berdirinya usaha Vita Nas pada tahun 2012 bertempat di Desa Sikasur RT.07

RW.05 Kecamatan Belik Kabupaten Pemalang. Awalnya usaha ini hanya memproduksi sirup buah nanas madu. Namun, seiring berjalannya waktu usaha Vita Nas ini membuat dua produk baru yaitu minuman sari buah nanas dan cocktail nanas.

Vita Nas memiliki produk tiga jenis, yaitu produk sirup nanas, minuman sari buah nanas dan cocktail nanas. Masing-masing produk memiliki kemasan yang berbeda-beda.

Proses pembuatan olahan buah nanas madu, yaitu :

a. Nanas madu segar dikupas kulitnya menggunakan alat berupa pisau, kemudian nanas madu dibersihkan dengan air bersih.

b. Nanas madu yang sudah di bersihkan kemudian dihancurkan menggunakan blender

c. Hasil ampas nanas madu dipisahkan dengan sari buahnya. Ampas nanas madu bisa digunakan untuk selai nanas madu, sedangkan sari buahnya digunakan untuk pembuatan sari buah nanas.

d. Sari buah nanas madu kemudian di masak menggunakan wajan dan ditambahkan air serta gula pasir. Perbandingan untuk 1 liter sari buah nanas bisa ditambahkan 4 liter air dan 2 ons gula pasir.

e. Sari buah nanas yang sudah matang kemudian di pindahkan ke wadah besar, kemudian sari buah nanas dituangkan kedalam cup serta botol.

f. Sari buah nanas yang sudah dituangkan ke cup kemudian ditutup dengan tutup plastik yang sudah disediakan menggunakan mesin cup sealer.

g. Produk olahan sirup nanas madu cara pembuatannya seperti sari buah nanas madu, akan tetapi ditambahkan lebih banyak gula sampai mengental.

\section{Uji Validitas dan Reliabilitas}

\section{a. Uji Validitas}

Menurut Suharsimi Arikunto dalam Setyawan (2015) "Validitas adalah suatu ukuran yang menunjukan tingkat-tingkat kevalidan atau kesahihan suatu instrumen". Berdasarkan Tabel 1. menunjukkan bahwa 18 butir pernyataan (instrumen) yang valid, semuanya dapat mewakili untuk dijadikan sebagai suatu pernyataan. 
Tabel 1. Uji Validitas Instrumen

\begin{tabular}{llll}
\hline Pernyataan & r hitung & r tabel & Keterangan \\
\hline item 1 & 0,530 & 0,444 & Valid \\
item 2 & 0,597 & 0,444 & Valid \\
item 3 & 0,569 & 0,444 & Valid \\
item 4 & 0,537 & 0,444 & Valid \\
item 5 & 0,897 & 0,444 & Valid \\
item 6 & 0,530 & 0,444 & Valid \\
item 7 & 0,591 & 0,444 & Valid \\
item 8 & 0,476 & 0,444 & Valid \\
item 9 & 0,501 & 0,444 & Valid \\
item 10 & 0,501 & 0,444 & Valid \\
item 11 & 0,540 & 0,444 & Valid \\
item 12 & 0,516 & 0,444 & Valid \\
item 13 & 0,446 & 0,444 & Valid \\
item 14 & 0,469 & 0,444 & Valid \\
item 15 & 0,504 & 0,444 & Valid \\
item 16 & 0,476 & 0,444 & Valid \\
item 17 & 0,549 & 0,444 & Valid \\
item 18 & 0,529 & 0,444 & Valid \\
\hline
\end{tabular}

Sumber : Analisis Data Primer, 2020

\section{b. Uji Reliabilitas}

Reliabilitas item dalam penelitian ini diuji dengan internal consistency, dilakukan dengan mencobakan item sekali saja yang kemudian data yang diperoleh dianalisis dengan beberapa teknik. Sedangkan untuk uji reliabilitas item digunakan rumus Alpha Cronbach yaitu :

$$
r 11=\left(\frac{k}{(k-1)}\right)\left(1-\frac{\sum_{\sigma t^{2}}}{\sigma^{2} t}\right)
$$

Di mana :

r11 = Reliabilitas Instrumen

$\mathrm{k}=$ Banyaknya butir pertanyaan

$\Sigma_{\sigma t} 2=$ Jumlah varians butir

$\omega^{2} t=$ Varians total

Berdasarkan tabel 2. hasil uji reliabilitas instrumen dilakukan dengan menggunakan microsoft excel. Hasil koefisien reliabilitas adalah 0,857. Maka dapat dikatakan instrumen tersebut reliabel, karena nilai koefisien reliabilitasnya lebih besar sama dengan 0,6.

Tabel 2. Uji Reliabilitas Instrumen

\begin{tabular}{l|l|l|l}
\hline Variabel & Koefisien Reliabilitas & Koefisien Alpha & Keterangan \\
\hline Y & 0,857 & 0,6 & Reliabel \\
\hline
\end{tabular}

Sumber : Analisis Data Primer, 2020

\section{Identifikasi Faktor Internal}

\section{a. Produksi}

Proses produksinya, pengolahan produk Vita Nas membutuhkan 300 buah nanas madu segar yang menghasilkan minuman sari buah nanas ukuran $120 \mathrm{ml}$ sebanyak 270 kardus dan 
ukuran $180 \mathrm{ml}$ sebanyak 230 kardus dengan estimasi waktu 7 jam dari bahan baku mentah menjadi produk siap konsumsi dalam waktu sehari.

b. Pemasaran

Pemasaran merupakan cara yang dilakukan produsen untuk mendapatkan konsumen dan melayani secara lebih efisien, memperoleh keuntungan, dan bertanggung jawab terhadap masyarakat. Bauran pemasaran (marketing mix) merupakan aspek pemasaran yaitu, sebagai berikut :

1) Produk

Produk yang di hasilkan oleh Vita Nas saat ini beragam meliputi minuman sari buah nanas, sirup buah nanas dan cocktail nanas.

2) Tempat

Tempat (outlet) penjualan yang ada di Vita Nas berlokasi sangat strategis karena dekat dengan rest area.

3) Promosi

Promosi yang di gunakan oleh Vita Nas yaitu dengan memanfaatkan pameran dan bazar. Selain itu, Vita Nas juga memiliki website untuk sarana promosinya. Vita Nas juga tersedia di online shope seperti Shopee, Buka Lapak, Tokopedia. Akan tetapi, dalam pelaksanaannya penggunaan media internet dan website yang sudah tersedia tidak dimanfaatkan sebaik mungkin. Hal ini di karenakan tidak adanya tenaga kerja yang bertugas di bagian promosi.

4) Harga

Dalam hal ini, Vita Nas sangat memperhitungkan harga yang ditawarkan. Hal ini dilakukan karena olahan yang di produksi Vita Nas tanpa menggunakan bahan pengawet dan murni bahan alami.

c. Administrasi

Administrasi di Vita Nas sudah menerapkan administrasi yang baik. Usaha ini sudah memiliki struktur organisasi dan pencatatan penjualan. Dalam pencatatannya, Vita Nas mencatat hasil penjualannya setiap hari dan merekap hasil penjualannya dalam waktu per tahun.

d. Sumber Daya Manusia

Kekuatan sumber daya manusia dalam suatu organisasi semakin disadari keberadaannya sehingga manusia dipandang sebagai aset terpenting dari berbagai sumber daya dalam organisasi. Kuatnya posisi manusia dalam organisasi melebihi sumber daya lainnya seperti material, metode, uang, mesin, pasar sehingga mendorong para ahli memberi sumbangan teori tentang manajemen sumber daya manusia

Sumber daya manusia yang terlibat di Vita Nas berjumlah 15 orang. Tenaga kerja yang berada di Vita Nas sebanyak 13 orang karyawan. Ada beberapa bagian struktur organisasi dalam Vita Nas yaitu, bidang administrasi, bidang produksi, bidang gudang dan bidang bahan baku.

e. Teknologi

Faktor perlakuan adalah variasi bentuk irisan pada buah nanas yang terdiri dari 3 taraf yaitu irisan membujur, irisan dadu, dan irisan memanjang. Pengamatan penelitian meliputi umur simpan, susut bobot, kekerasan, vitamin C dan total padatan terlarut (TPT) (Maulidia, dkk, 2017).

Teknologi yang digunakan di Vita Nas sudah cukup memadai. Usaha ini memiliki mesin cup sealer sebanyak 2 buah dan mesin semi manual sebanyak 10 buah. Sistem perawatan mesin yang digunakan dalam produksi sesuai dengan Standar Operasional Prosedur (SOP).

Bahan-bahan pengemas yang ada saat ini dimulai dari yang sederhana sampai yang canggih yang dihasilkan dengan teknologi yang canggih pula. Semakin baik kualitas atau semakin canggih bahan kemasan tentu akan berbanding lurus dengan harga atau biaya yang dibutuhkan untuk mendapatkan atau menggunakannya. (Zawitri, 2017). 
Teknologi pangan, terutama teknologi penanganan bahan hasil pertanian, teknologi penyimpanan, teknologi pengolahan, teknologi pengemasan pangan, teknologi distribusi pangan, dan lain sebagainya mempunyai peran penting dalam menekan kehilangan, meningkatkan keanekaragaman pangan, meningkatkan keamanan pangan, dan meningkatkan nilai gizi pangan. (Hariyadi, 2010).

\section{Identifikasi Faktor Kekuatan}

1) Memiliki pencatatan penjualan yang baik.

2) Bahan baku melimpah.

3) Produk memiliki ciri khas.

4) Diversifikasi Produk

5) Adanya pelatihan dan pembekalan ketrampilan tenaga kerja.

6) Struktur organisasi berjalan dengan baik.

7) Memiliki peralatan yang memadai dan transportasi khusus.

\section{Identifikasi Faktor Kelemahan}

1) Kurang maksimal dalam penggunaan website dan media internet.

2) Daerah pemasaran hanya lingkup Pemalang sekitarnya.

3) Tidak adanya sales marketing.

4) Tempat packing sempit.

Tabel 3. Rekapitulasi Faktor Internal Terbobot Analisis Matrik IFE.

\begin{tabular}{|c|c|c|c|c|}
\hline \multicolumn{5}{|c|}{ Faktor Internal } \\
\hline & Kekuatan & Bobot & Peringkat & $\begin{array}{l}\text { Bobot } x \\
\text { Peringkat }\end{array}$ \\
\hline 1 & $\begin{array}{l}\text { Memiliki pencatatan setiap } \\
\text { penjualan }\end{array}$ & 0,14 & 3 & 0,41 \\
\hline 2 & Bahan baku melimpah & 0,17 & 4 & 0,69 \\
\hline 3 & Produk memiliki ciri khas & 0,16 & 4 & 0,62 \\
\hline 4 & $\begin{array}{l}\text { Diversifikasi produk } \\
\text { Adanya pelatihan dan }\end{array}$ & 0,12 & 4 & 0,48 \\
\hline 5 & $\begin{array}{l}\text { pembekalan keterampilan } \\
\text { tenaga kerja }\end{array}$ & 0,09 & 3 & 0,26 \\
\hline 6 & $\begin{array}{l}\text { Struktur organisasi berjalan } \\
\text { dengan baik }\end{array}$ & 0,07 & 3 & 0,21 \\
\hline 7 & $\begin{array}{l}\text { Memiliki peralatan yang } \\
\text { memadai dan transportasi } \\
\text { khusus }\end{array}$ & 0,10 & 3 & 0,31 \\
\hline
\end{tabular}

\section{Kelemahan}

\begin{tabular}{lllll} 
Kurang maksimalnya & & \\
1 & $\begin{array}{l}\text { penggunaan website dan } \\
\text { media internet }\end{array}$ & 0,05 & 0,10 \\
2 & $\begin{array}{l}\text { Daerah pemasaran hanya } \\
\text { lingkup pemalang sekitarnya }\end{array}$ & 0,02 & 1 & 0,02 \\
3 & $\begin{array}{l}\text { Tidak adanya Sales } \\
\text { Marketing } 0,05\end{array}$ & 1 & 0,05 \\
4 & 0,03 & 2 & 0,07 \\
\hline Tempat packing sempit & $\mathbf{1}$ & & $\mathbf{3 , 2 2}$ \\
\hline
\end{tabular}

Sumber : Analisis Data Primer, 2020

\section{Identifikasi Faktor Eksternal}

a. Pesaing

Pesaing bagi usaha Vita Nas ini yaitu usaha dengan bahan baku yang sama namun dengan jenis produk yang berbeda.

b. Bahan baku 
Bahan baku yang didapatkan untuk usaha olahan nanas madu Vita Nas ini berasal dari Desa Beluk Kecamatan Belik.

c. Konsumen

Konsumen dari produk Vita Nas cenderung masyarakat yang berada di daerah Pemalang dan sekitarnya.

d. Pemerintah

Peran pemerintah dalam usaha Vita Nas ini sangat penting. Pemerintah setempat sangat mendukung usaha Vita Nas yang ada di Desa Sikasur.

\section{Identifikasi Faktor Peluang}

1) Adanya kerja sama dengan pengusaha lain.

2) Kestabilan harga bahan baku.

3) Memiliki konsumen tetap.

4) Bantuan dan dukungan dari pemerintah setempat.

\section{Identifikasi Faktor Ancaman}

1) Masih mengandalkan tengkulak.

2) Selera konsumen.

3) Harga relatif mahal.

Tabel 4. Rekapitulasi Faktor Ekternal Terbobot Analisis Matrik EFE.

\begin{tabular}{|c|c|c|c|c|}
\hline \multicolumn{5}{|c|}{ Faktor Eksternal } \\
\hline & Peluang & Bobot & Peringkat & $\begin{array}{l}\text { Bobot } \mathbf{x} \\
\text { peringkat }\end{array}$ \\
\hline 1 & $\begin{array}{l}\text { Adanya kerja sama dengan } \\
\text { pengusaha lain }\end{array}$ & 0,17 & 4 & 0,67 \\
\hline 2 & Kestabilan harga bahan baku & 0,13 & 3 & 0,38 \\
\hline 3 & Memiliki konsumen tetap & 0,21 & 3 & 0,63 \\
\hline \multirow[t]{2}{*}{4} & $\begin{array}{l}\text { Bantuan dan dukungan dari } \\
\text { pemerintah setempat }\end{array}$ & 0,25 & 4 & 1,00 \\
\hline & Ancaman & & & \\
\hline 1 & Masih mengandalkan tengkulak & 0,13 & 2 & 0,25 \\
\hline 2 & Selera konsumen & 0,08 & 2 & 0,17 \\
\hline \multirow[t]{2}{*}{3} & Harga relatif mahal & 0,04 & 1 & 0,04 \\
\hline & Total & 1 & & 3,13 \\
\hline
\end{tabular}

Sumber : Analisis Data Primer, 2020

\section{Internal Eksternal Matriks (Matriks IE)}

Berdasarkan gambar 1. diketahui bahwa usaha Vita Nas berada pada daerah I yaitu tumbuh dan kembangkan, hal ini berarti Vita Nas memiliki peluang untuk terus tumbuh dan terus berkembang. Strategi yang sesuai untuk daerah ini adalah strategi intensif seperti penetrasi pasar, pengembangan pasar dan pengembangan produk.

Pengembangan pasar dan pengembangan produk dapat dilakukan dengan cara memperluas daerah pemasaran produk Vita Nas, selain membuat atribut kualitas produk seperti desain produk dan kemasan produk agar dapat meningkatkan jumlah konsumen, memenuhi permintaan pasar serta memperkenalkan potensi Sumber Daya Alam dan nilai tambah produk lokal suatu daerah di tingkat nasional atapun internasional.

Analisis matrik IE ini sekaligus menjadi pembuktian bahwa Vita Nas memiliki potensi ekonomi yang layak dikembangkan dengan menggunakan kekuatannya untuk mengatasi kelemahan dan menghadapi ancaman terutama terkait tengkulak dalam perolehan bahan baku serta dapat memanfaatkan peluang. 


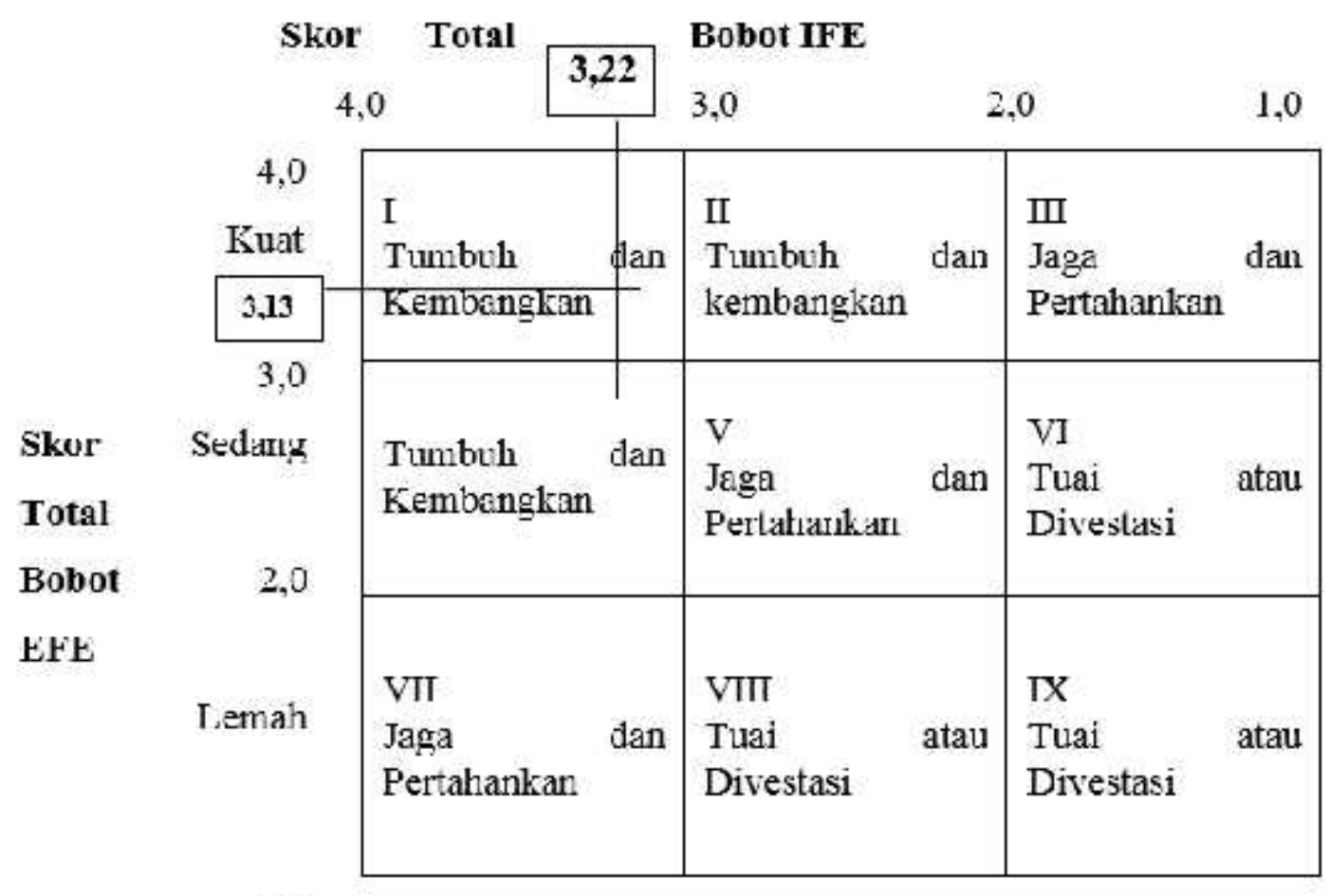

1,0

Gambar 1. Total Matriks IE

\section{Analisis SWOT (Matriks SWOT)}

Kadek, dkk (2019) meneliti tentang strategi pemasaran nanas dengan analisis data SWOT dengan menggunakan IFE (Internal Factors Evaluasi) matriks, EFE Matrix (External Factors Evaluation), dan IE (Internal External) Matrix di Kabupaten Konawe Selatan yang merupakan salah satu kabupaten di Sulawesi Tenggara. Hasil penelitian menunjukkan bahwa strategi pemasaran nanas yang tepat adalah strategi pertumbuhan diversifikasi konsentrasi

Matriks ini menghasilkan empat sel kemungkinan alternatif strategi, yaitu strategi SO, strategi WO, strategi WT, dan strategi ST.

a. Strategi SO : Menggunakan kekuatan untuk memanfaatkan peluang.

1) Memperkuat kerja sama dan koordinasi antara pengusaha dengan dinas ataupun pemerintah setempat.

2) Mengembangkan jaminan mutu produk .

3) Meningkatkan kerjasama dan membuat inovasi terbaru dengan pengusaha lain.

b. Strategi WO : Meminimalkan kelemahan untuk memanfaatkan peluang.

1) Meningkatkan promosi produk dengan cara mengikuti pameran sehingga dapat memperkenalkan produk ke masyarakat luas.

c. Strategi ST : Menggunakan kekuatan untuk mengatasi ancaman.

1) Membangun kerja sama langsung dengan petani.

2) Mempertahankan kualitas produk.

Hal ini dilakukan agar setiap hari pengusaha mampu mencukupi kebutuhan konsumen dan kepercayaan dari pelanggan tetap terjaga sehingga tidak berpindah ke tempat lain. (Fatmawati, 2009).

3) Memberikan pelayanan terbaik kepada konsumen.

d. Strategi WT : Meminimalkan kelemahan untuk mengatasi ancaman.

1) Meningkatkan kegiatan promosi dengan website dan media internet untuk menarik konsumen.

Menurut Tenywa et al.( 2018) rantai pasok dimulai dengan input petani ke pedagang sebagai pemain utama dalam produksi dan pemasaran ke berbagai pelaku di pasar lokal dan 
perkotaan. Sehingga Vita Nas bisa mengikuti strategi yang dalam inovasi berkelanjutan dengan tujuan kedepan mendapatkan keuntungan.

Pengembangan produk dapat dilakukan dengan cara memperluas daerah pemasaran produk Vita Nas dan membuat kemasan menarik dan atribut kualitas produk seperti desain produk sehingga dapat meningkatkan jumlah penjualan ke konsumen.

\section{KESIMPULAN DAN SARAN \\ Kesimpulan}

Berdasarkan analisis SWOT yang dilakukan pada Vita Nas didapatkan bahwa usaha olahan nanas madu memiliki banyak kekuatan dan peluang yang dapat dimanfaatkan untuk mengatasi kelemahan dan ancaman dari usaha kompetitor. Vita Nas merupakan usaha yang telah memiliki "nama" dibandingkan usaha lainnya yang serupa. Kekuatan yang dimiliki Vita Nas adalah adanya pencatatan pada setiap penjualan, bahan baku melimpah, produk memiliki ciri khas, diversifikasi produk, adanya pelatihan dan pembekalan keterampilan tenaga kerja, struktur organisasi berjalan dengan baik dan memiliki peralatan yang memadai serta adanya transportasi khusus. Sedangkan kelemahannya adalah kurang maksimalnya penggunaan website dan media internet, daerah pemasaran hanya lingkup Pemalang sekitarnya, tidak adanya Sales Marketing dan tempat packing yang sempit.

Alternatif strategi yang dapat diterapkan dalam pengembangan usaha olahan nanas madu di Vita Nas adalah Strategi S-O: Memperkuat kerja sama dan koordinasi antara pengusaha dengan dinas ataupun pemerintah setempat, meningkatkan kerjasama dan membuat inovasi terbaru dengan pengusaha lain dan mengembangkan jaminan mutu produk. Strategi W-O: Meningkatkan promosi produk dengan cara mengikuti pameran sehingga dapat memperkenalkan produk ke masyarakat luas. Strategi S-T: Membangun kerjasama langsung dengan petani, mempertahankan kualitas produk dan memberikan pelayanan terbaik kepada konsumen. Strategi W-T: Meningkatkan kegiatan promosi dengan website dan media internet untuk menarik konsumen.

Saran dari penelitan ini adalah: perlunya tenaga kerja di bidang promosi untuk meningkatkan dan mengenalkan produk dengan cara memanfaatkan teknologi informasi seperti penggunaan website dan media internet yang sudah dimiliki. Selain itu, pengusaha juga perlu memperhatikan atribut kualitas produk seperti desain dan kemasan produk, sehingga dapat menimbulkan kepuasan pada pelanggan untuk membeli produk. Perluasan tempat pengemasan juga diperlukan agar tenaga kerja lebih leluasa dan nyaman dalam bekerja.

\section{DAFTAR PUSTAKA}

Agroforestry, Traditional. 2019. "Value Chain Analysis of Pineapple (Ananas Comosus) Production and Marketing from Traditional Agroforestry System, Southern Ethiopia." Food Science and Quality Management (October):0-10.

Astoko, Endro. 2019. "Konsep Pengembangan Agribisnis Nanas (Ananas Comosus L. Merr.) Di Kabupaten Kediri Provinsi Jawa Timur." Habitat 30(3):111-22.

BPS. 2016. "Kabupaten Pemalang Dalam Angka Tahun 2016." Badan Pusat Statistik Provinsi Jawa Tengah.

Dwiastuti, Rini. 2017. Metode Penelitian Sosial Ekonomi Pertanian: Dilengkapi Pengenalan Berbagai Perspektif Pendekatan Metode Penelitian. Cetakan Pe. Malang: UB Press.

Fatmawati, Nurul Laela. 2009. "Strategi Pengembangan Industri Kecil Tempe Di Kecamatan Pedan Kabupaten Klaten.” Universitas Sebelas Maret Surakarta.

Fitri, Melati, Yurisinthae Erlinda, and Eva Dorosa. 2014. "Strategi Pengembangan Agribisnis Nenas Di Kabupaten Kubu Raya Kalimantan Barat." Jurnal Social Economic of Agriculture 3(35):5.

Hariyadi, Purwiyatno. 2010. "Penguatan Industri Penghasil Nilai Tambah Berbasis Potensi Lokal Peranan Teknologi Pangan Untuk Kemandirian Pangan.” Pangan 19(4):295-301.

Kadek Yudiastini, Abdi, and Abdul Gafaruddin. 2019. "Strategi Pemasaran Nanas (Ananas Comosus)Di Desa Wonua Morini Kecamatan Sabulakoa Kabupaten Konawe Selatan.” Jurnal Agribisnis Dan Ilmu Sosial Ekonomi Pertanian 4(6):142-47.

Maulidia, Lisa, Rita Khatir, and Ratna Ratna. 2017. "Pengaruh Bentuk Irisan Nanas Terhadap Mutu Simpan Terolah Minimal." Jurnal Ilmiah Mahasiswa Pertanian 2(3):266-75. 
Setyawan, Robi. 2015. "Penerapan Analisis SWOT Sebagai Landasan Merumuskan Strategi Pemasaran Usaha Jasa Sewa Mobil 'AMIN-AMIN' Transport Tours and Travel Ambarketawang Sleman Yogyakarta.” Universitas Negri Yogyakarta.

Taherdoost, Hamed. 2018. "Validity and Reliability of the Research Instrument; How to Test the Validation of a Questionnaire/Survey in a Research." SSRN Electronic Journal 5(3):28-36.

Tenywa, Moses M., Sospeter O. Nyamwaro, Rebecca Kalibwani, Robin Buruchara, and Fatunbi Oluwole. 2018. "Volume 2 No : 18 ( 2018 ) Innovation Opportunities in Sorghum Production in Uganda." 2(April):1-20.

Zawitri, Sari. 2017. "IbM KELOMPOK TANI DESA SUNGAI RASAU KECAMATAN." $8(2): 147-52$. 